Open access to Pharmaceutical and Medical research

C 2015, publisher and licensee JDDT, This is an Open Access article which permits unrestricted noncommercial use, provided the original work is properly cited

\title{
STUDY ON DRUG PRESCRIBING PATTERN IN DENGUE PATIENTS IN A TERTIARY CARE HOSPITAL: A TOOL TO TEACH CLINICAL PHARMACOLOGY
}

\author{
Dr. Shaktibala Dutta, *Dr. Mirza Atif Beg, Dr. Shalu Bawa, Dr. Mohammad Anjoom, Dr. Subhash Vishal \\ Department of Pharmacology, SGRRIM\&HS, Patel Nagar, Dehradun, India
}

Received 06 Feb 2015; Review Completed 14 March 2015; Accepted 14 March 2015, Available online 15 March 2015

\begin{abstract}
Introduction and Aim: Dengue fever (DF) is the most common arboviral infection of mankind gaining global attention. Data about drug usage patterns in DF in India are lacking.The present study was undertaken to analyze drug utilization pattern of dengue infections to teach certain basic skills to MBBS students which will form an integral component of practising rational therapeutics.

Methods: A total no of 122 cases were followed up by the $5^{\text {th }}$ semester $2^{\text {nd }}$ Professional undergraduate students in the department of pharmacology at hospital wards of SGRRIM \&HS, Dehradun from June 2012 to July 2014. Patients were analysed on various parameters using WHO drug use indicators and National List of Essential Medicines.

Results: A total of 122 prescriptions were analyzed. Male:Female ratio was $(72.95 \%, 27.05 \%)$ Age wise distribution of patients was done: $0-15$ years were $9(7.34 \%), 16-30$ years were $45(36.88 \%), 31-45$ years were $46(37.70 \%), 46-60$ years were 18 $(14.75 \%)$ and $>60$ years were $4(3.28 \%)$. A total of 614 drugs were prescribed. $169(27.52 \%)$ antimicrobials, $99(16.12 \%)$ antipyretics, $91(14.82 \%)$ antacids, 65(10.59\%) multivitamins, 55(8.96\%) antiemetics and $135(21.99 \%)$ in miscellaneous category were prescribed. 243(40.23\%) oral drugs and 361(59.77\%) injectable drugs were prescribed. 5.03 drugs per prescription were prescribed. $377(62.42 \%)$ drugs were prescribed from National Essential Medicine List.100\% drugs were prescribed by brand names.

Conclusion: Majority of the drugs were prescribed from national essential medicine list. As the incidence of DF is increasing with epidemics, the demand for specific treatment guidelines is in great need.

Key words: Dengue fever, drug utilisation pattern, rational prescribing.
\end{abstract}

\section{INTRODUCTION}

Dengue fever (DF) is a vector-borne viral infection of global importance ${ }^{1}$. Dengue is the most rapidly spreading mosquito-borne viral disease in the world. In the last 50 years, incidence has increased 30-fold with increasing geographic expansion to new countries and, in the present decade, from urban to rural settings. An estimated 50 million dengue infections occur annually and approximately 2.5 billion people live in dengue endemic countries ${ }^{2}$. Dengue has a wide spectrum of clinical presentations, often with unpredictable clinical evolution and outcome ${ }^{3}$. In India, dengue infection has been known to be endemic for over two centuries as a benign and self-limited and epidemics have been reported in many parts of the country. Data about drug usage patterns in DF in India are particularly lacking ${ }^{4}$. Drug utilization research facilitates the rational use of drugs in populations and hence it is important for clinical, educational and economic reasons ${ }^{5,6}$. In order to improve rational prescribing of medicines, there is a need to introduce clinical pharmacology at the undergraduate level. The life-long skills need to be introduced at the very beginning of clinical training. The aim of teaching clinical pharmacology to undergraduate students is to impart the knowledge and skills that each and every student should learn to prescribe drugs safely and effectively and to maintain his efficient competence throughout his/her professional life 7 . Keeping the above facts in consideration, the objective of the present study was to understand the prescribing patterns in dengue fever in order to impart clinical pharmacology knowledge to the MBBS 2nd professional students.
*Corresponding Author: Dr. Mirza Atif Beg Assoc. Prof., Department of Pharmacology, SGRRIM\&HS, Patel Nagar, Dehradun, India Email: mabeg1997@gmail.com Contact No.: 9415839837 


\section{MATERIAL AND METHODS}

A total no of 122 cases were followed up by the $5^{\text {th }}$ semester $2^{\text {nd }}$ Professional Undergraduate students during 2nd professional MBBS in the department of Pharmacology at hospital ward of SGRRIM \& HS Dehradun from June 2012 to July 2014. The prescriptions were discussed and analyzed in the Department of Pharmacology for trends of drugs use \& rationality of prescriptions in dengue fever. Approval of the Institutional Ethics Committee was obtained prior to the commencement of the study. The WHO indicators which were analyzed were: Drug Formulations, Drugs Prescribed from National List of Essential Medicines (NLEM) 2013, Generic drugs and drugs prescribed per prescription.

\section{RESULTS}

A total of 122 dengue patients records were collected by MBBS 2nd professional students. Male: Female \%age was $89(72.95 \%), 33(27.05 \%)$. Age wise distribution of patients was done, there were $9(7.34 \%)$ patients in $0-15$ year age group, $45(36.88 \%)$ in 16-30 year group, $46(37.70 \%)$ in $31-45$ years, $18(14.75 \%)$ in $46-60$ years and $4(3.28 \%)$ in $>60$ years age group respectively (Table 1). Intravenous fluids (IVFs) were given to all the patients. A total of 614 drugs were prescribed. $169(27.52 \%)$ antimicrobials, 99(16.12\%) antipyretics, 91(14.82\%) antacids, 65(10.59\%) multivitamins,
$55(8.96 \%)$ antiemetics and 135(21.99\%) miscellaneous drugs were prescribed (Figure 1). A total of $169(27.52 \%)$ antimicrobials were prescribed. Cefoperazone was most commonly prescribed antimicrobial in 73(43.19\%), followed by Doxycyclin in $26(15.38 \%)$, Ceftriaxone in $15(8.88 \%)$, Artesunate in $13(7.69 \%)$, Azithromycin in $9(5.33 \%)$, Ceftazidime in $6(3.55 \%)$, Ciprofloxacin and Metronidazole in $5(2.96 \%)$ and miscellaneous drugs in $17(10.06 \%)$ patients (Figure 2). 243(39.58\%) oral drugs and $371(60.42 \%)$ injectable drugs were given (Table 2$)$. The drugs prescribed per prescription were 5.03. $377(62.42 \%)$ drugs were prescribed from National List of Essential Medicines (NLEM 2013). All drugs were prescribed by their respective brand names (Table 2).

Table 1: Demographic Profile

\begin{tabular}{|l|l|}
\hline Total patients & 122 \\
\hline Male:Female & $89(72.95 \%): 33(27.05 \%)$ \\
\hline $0-15$ years & $9(7.38 \%)$ \\
\hline 16-30 years & $45(36.88 \%)$ \\
\hline $31-45$ years & $46(37.70 \%)$ \\
\hline $46-60$ years & $18(14.75 \%)$ \\
\hline$>60$ years & $4(3.28 \%)$ \\
\hline
\end{tabular}

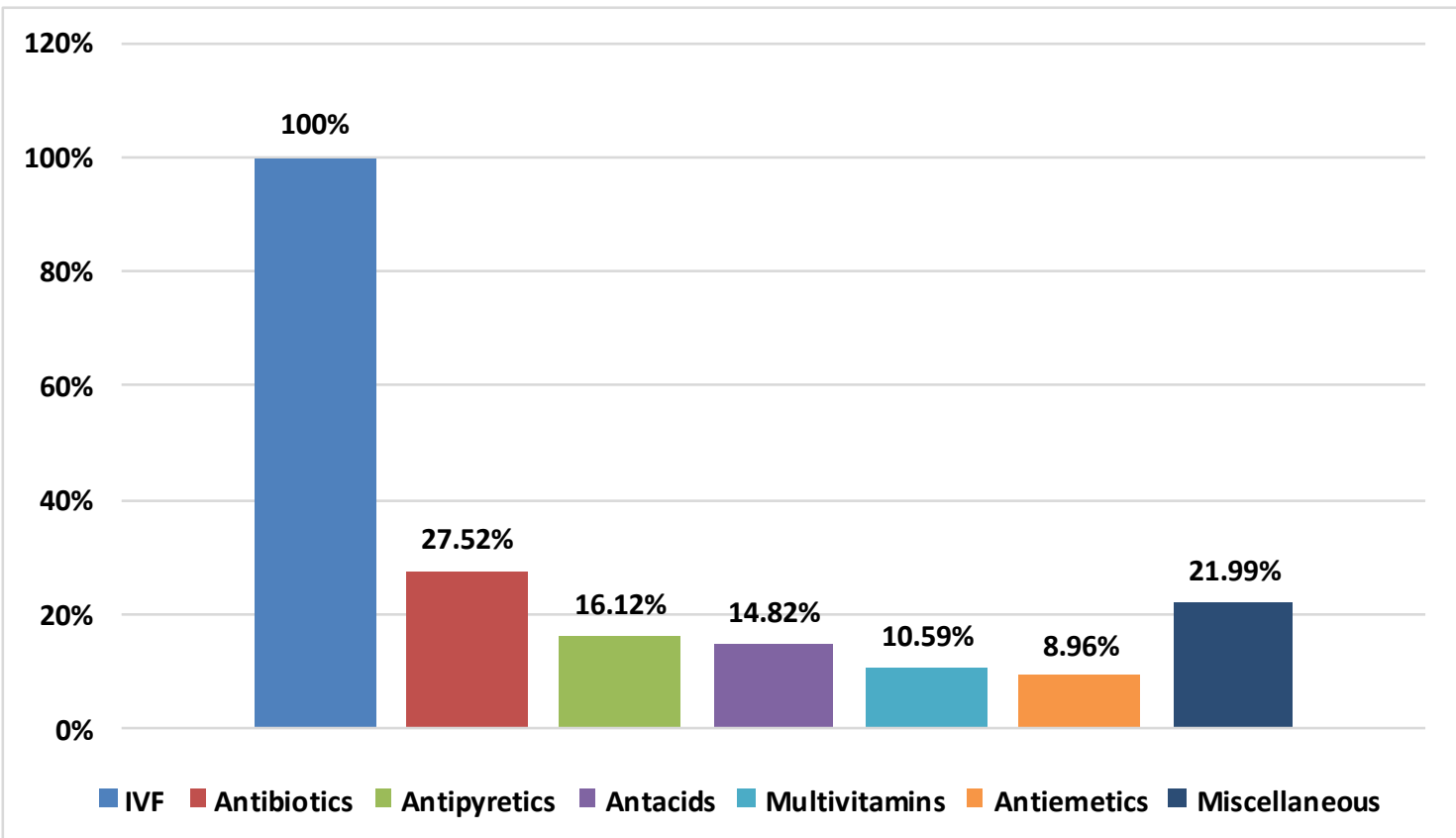

Figure 1: Prescription Pattern 


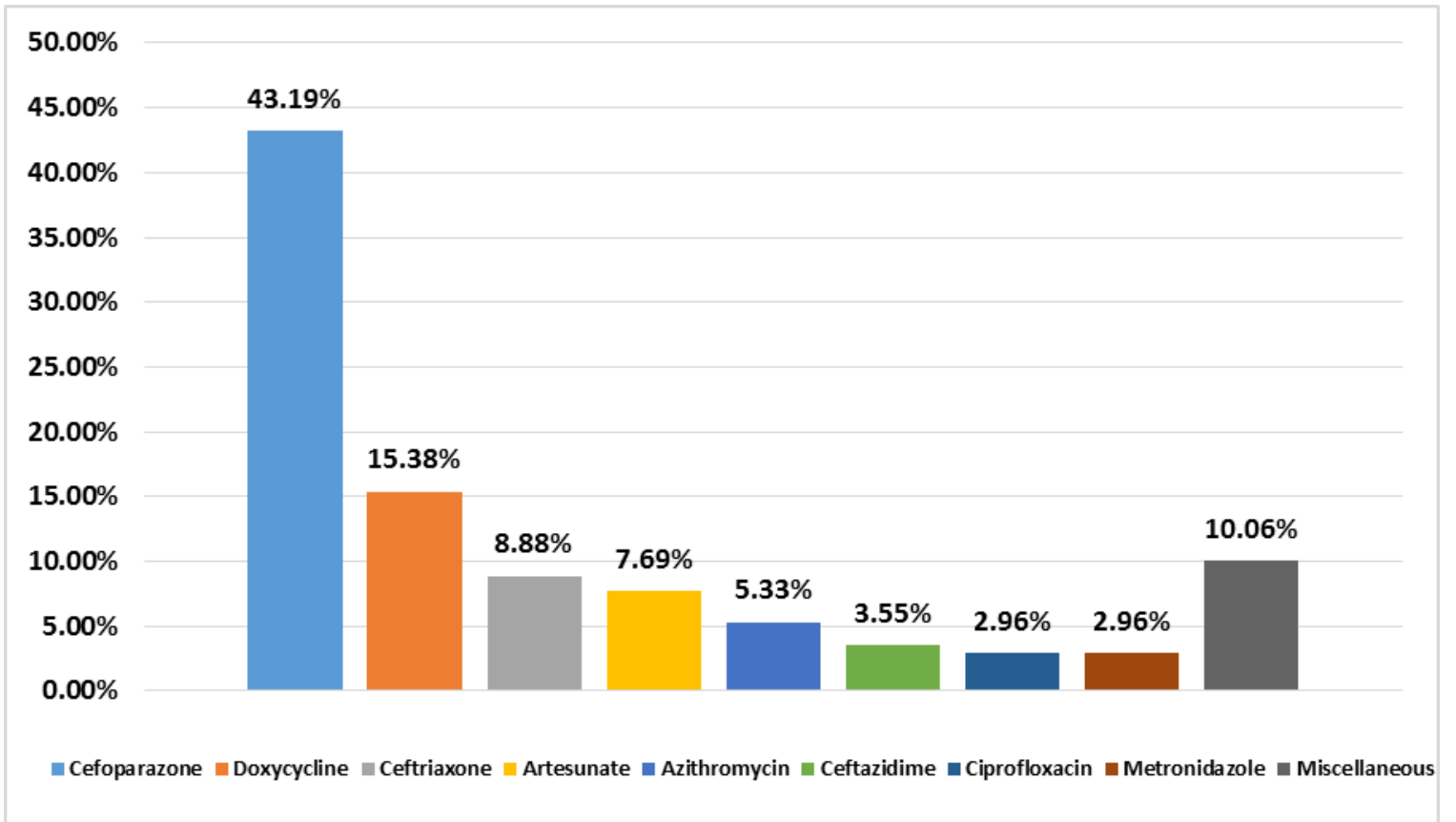

Figure 2: Antimicrobials Prescribed

Table 2: WHO drug use indicators

\begin{tabular}{|l|l|l|}
\hline Drugs Per Prescription & $\mathbf{5 . 0 3}$ \\
\hline Drug formulation & Oral & $\mathbf{2 4 3 ( 3 9 . 5 8 \% )}$ \\
\cline { 2 - 3 } & Injectable & $\mathbf{3 7 1}(60.42 \%)$ \\
\hline $\begin{array}{l}\text { Drugs from National List of Essential } \\
\text { Medicines 2013 }\end{array}$ & $\mathbf{3 7 7 ( 6 2 . 4 2 \% )}$ \\
\hline Drugs prescribed by Brand Names & $\mathbf{1 0 0 \%}$ \\
\hline
\end{tabular}

\section{DISCUSSION}

The present study was an attempt to develop clinical skills in MBBS 2nd professional students about rational prescribing. The importance was laid on WHO drug use indicators. Students learnt about the demographic profile of patients i.e. number of male and female patients and age wise distribution of patients. Dengue was seen in more male patients as compared to females in the present study. This was comparable with previous studies by Hafeez et al ${ }^{8}$ and Rani U et al ${ }^{9}$ where majority of the patients were male patients. Most of the patients were seen in 16-45 year age group which was comparable with previous study ${ }^{9}$. The present study was aimed to teach the importance of pharmacotherapy and rational use of drugs to undergraduate students as explained in previous study ${ }^{10}$. Students were able to categorize the drugs as antimicrobials, antipyretics, antacids, multivitamins, antiemetics and other drugs. Thus they developed analytical skills and understood the prescribing trends in dengue fever in the hospital. In the management of dengue fever, priority treatment included intravenous fluids. This was similar to previous studies ${ }^{8,9}$. Intravenous rehydration has been shown to reduce the case fatality rate to less than $1 \%$ of severe cases 11. Antimicrobials were the most commonly prescribed medications in our study which (c) 2011-15, JDDT. All Rights Reserved was not comparable with other studies ${ }^{8,9}$. The use of antimicrobials was done to prevent secondary bacterial infections and in very sick patients. Cefoperazone was the most commonly prescribed antimicrobial in our study. This was comparable with previous study by Kiran Nagaraju et al where cephalosporins were most commonly used to treat patients with dengue fever ${ }^{12}$. Prescription of antipyretics, antacids, multivitamins and antiemetics was mainly for symptomatic management of $\mathrm{DF}$ as seen in previous studies ${ }^{8,9}$. The most commonly preferred route of administration was parenteral route. Since majority of dengue patients will have gastrointestinal disturbances like nausea and vomiting the prescription preference to parenteral formulations was justified. This was similar to previous study ${ }^{13}$. Majority of the drugs were prescribed from NLEM probably depicting the rational use of drugs in this study. This was seen in accordance with other study ${ }^{9}$. In our study drugs prescribed per prescription was higher as compared to previous study ${ }^{9}$. All the drugs were prescribed by their respective brand names. Prescription of drugs by their generic names helps in the identification of the products, making it easier for the prescribers, dispensers and users to choose between other alternatives competing in terms of quality, price or convenience $^{14,15}$. Hence the generic drug prescriptions 
should be increased over prescriptions with branded drugs.

In our study, an attempt has been made to teach undergraduate medical students about the significance of drug utilization study in dengue patients. The main purpose of undergraduate medical curriculum is to develop the requisite diagnostic and therapeutic skills of a basic doctor. The practical training has also to be need based and relevant ${ }^{16}$. Mere theoretical teaching is not enough. The students must be taught certain basic skills which form an integral component of practicing rational therapeutics ${ }^{17}$. Analysing drugs on the above grounds would give a broader perspective of drug prescription patterns and may help in developing specific treatment guidelines in the management of DF.
Limitations of the study were the small sample size, inability to report the adverse drug reactions and drug interactions by the students.

\section{CONCLUSION}

The present study revealed that dengue infection was more prevalent in males in the age group of 16-45 years. Intravenous fluids constituted the mainstay of treatment in all the patients. Antimicrobials were the most frequently prescribed drugs. Majority of drugs were prescribed from National List of Essential Medicines which could be attributed to rationality of prescriptions. As the incidence of DF is increasing with epidemics the demand for specific treatment guidelines is in great need. Training of students through such drug utilization studies gives a clinical orientation to the MBBS students, which have a bearing on their further training in final professional and internship.

\section{REFERENCES:}

1. Balasubramanian S, Ramachandran B, Amperayani S. Dengue Viral Infection in Children: A Perspective. Arch Dis Child 2012;97(10):907-12.

2. WHO. Dengue and dengue haemorrhagic fever. Fact sheet No 117, revised May 2008. Geneva, World Health Organization, 2008.

3. Dengue: Guidelines for Diagnosis, Treatment, Prevention and Control. World Health Organization 2009. WHO/HTM/NTD/DEN/2009.

4. Gupta E, Dar L, Kapoor G, Broor S. The changing epidemiology of dengue in Delhi, India, Virol Journal 2006 3: 92.

5. World Health Organization: Introduction to Drug Utilization Research 2003;1-49.

6. Uppal R, Chhabra A, Narang A. Pattern of drug use in Neonatal Intensive Care Unit. Indian Journal of Paediatrics 1984;35:647-49.

7. Gitanjali B, Shashindran $\mathrm{CH}$. Curriculum in clinical pharmacology for medical undergraduates of India. Indian $\mathrm{J}$ Pharmacol 2006;38:108-14.

8. Hafeez AK, Akheel MA, Ashfaque A, Meera NK. Prescribing Pattern for the treatment of dengue in a tertiary care hospital, BangaloreIndia. Pharma tutor 2011.

9. Rani U, Kamath SG, Varun HV, Aithal S, Patil U. Prescribing Patterns in Dengue Fever in Paediatric Patients in a tertiary care hospital: A retrospective cross sectional study. Int. J. Pharm. Sci. Rev. Res 2014;24(2):112-8.

10. Kaushal S, Chopra SC, Arora S. Modifications in the undergraduate MBBS pharmacology practical curriculum: The DMCH model. Indian J Pharmacol 2007;39(1):57-59.

11. Soegijanto S, Budiyanto, Kartika, Taufik, Amor. The monthly changing of the lowest population dengue virus infection in patient at Soerya hospital. Indonesian Journal of Tropical and Infectious disease 2011;2(1):20-24.

12. Nagaraju K, Fard N M, Surekha G, Vishal S, Bolouri A. Drug utilisation evaluation of Cephalosporins, Macrolides, Quinolones antibiotics in KIMS hospital. IJRPC 2014;4(4):841-49.

13. Dengue Fever, Centre for Disease Control 2013;1-2. Available from internet http://www.nt.gov.au/ health.

14. Tabish A, Jha RK, Rathod AM, Rathod RM, Gupta VK, Prescribing trend of analgesics in a tertiary health care setup of rural Vidarbha: A critical appraisal RJPBCS 2012;3(3):566-71.

15. Rahman MS, Begum ZA, Samad MK. Prescribing pattern of nonsteroidal anti-inflammatory drugs at outpatient departments of teaching hospitals. Bangladesh J Pharmacol 2007;2:1-6.

16. Hariharan TH. Need for changes in practical pharmacology curriculum of medical undergraduates. Indian $\mathrm{J}$ Pharmacol $2004 ; 36$ (3): 181 .

17. Towards a more meaningful teaching of pharmacology. Indian J Pharmacol 2004;36(4):259-61. 